\title{
Organic field effect transistors (OFETs) in environmental sensing and health monitoring: A review
}

\author{
Sandeep G. Surya ${ }^{\text {a, b*, Harshil N. Raval }}{ }^{\text {b }}$ Rafiq Ahmad ${ }^{\text {a }}$, Prashant Sonar ${ }^{c}$, Khaled N. Salama ${ }^{\text {a }}$, \\ V Ramgopal Rao ${ }^{\mathrm{b} *}$
}

a Sensors lab, Advanced Membranes and Porous Materials Center, Computer, Electrical and Mathematical Science and Engineering Division, King Abdullah University of Science and Technology (KAUST), Saudi Arabia

b Electrical Engineering Department, Indian Institute of Technology Bombay, Mumbai - 400076, India c School of Chemistry, Physics and Mechanical Engineering, Queensland University of Technology, Brisbane, Australia.

Corresponding author e-mail: sandeep.surya@kaust.edu.sa, rrao@iitd.ac.in

\section{Abstract}

Organic field effect transistors (OFETs) have been the focus of sensing application research over the last two decades. In comparison to their inorganic counterparts, OFETs have multiple advantages, such as low-cost manufacturing, large area coverage, flexibility and readily tunable electronic material properties. To date, various organic semiconductors (OSCs), both polymers and small molecules, have been extensively researched for the purpose of developing the active channel layers in OFETs, enhancing their sensitivity and selectivity. However, OFET devices still need to be optimized to demonstrate reliable performance at the device level and in sensing applications. This review begins with an introduction of the OFETs with an emphasis on their geometry, materials (OSCs), fabrication process, and data analysis. After this, multiple applications are discussed and the progress regarding sensing elements and precisions is highlighted. In the end, the challenges and possible future directions of OFET arrays in embedded sensing platforms are presented.

Keywords OFETs, composites, bi-layer, VOCs, biosensor, gamma irradiation, selectivity, stability, sensitivity 


\section{Introduction}

Because of the ever-growing threat to human health and safety, a large number of researchers have focused on the topic of environmental sensors. Developing a common and cost-effective platform for sensing different environmental parameters is indeed the need of the hour. For the past four decades, researchers have been trying to address the same with an "electronic nose" (enose) platform [1]. Such a device requires mimicking an organic, biological nose in order to build an artificial detection platform. Like the olfactory receptor neurons (ORNs) that take care of sensing in a nose, a chemical block taking care of sensing analytes are utilized in the artificial structure [2]. The current e-nose platform is a multi-sensor package with provisions to detect minute quantities of chemicals such as a CNG leak, mining gases, and chemical warfare agents. Despite extensive research dating back decades and by the use of same principle of combinatorial selectivity, e-nose still cannot match the performance standard of a biological nose [3]. The advantage of an e-nose is that it can be designed to perform desired tasks in limited applications, for example for the breath analysis of tuberculosis (TB) patients [4].

Environmental sensing and health monitoring can be classified into the sensing of chemical analytes, ionizing radiation, pressure, humidity, and temperature, which is the focus of this review. For a sensor to be efficient it should satisfy the following criteria.

(a) Maximum surface-to-volume ratio of sensing element $[5,6]$

(b) Quick response and recovery times

(c) High Selectivity [7]

(d) Stability $[8,9]$

(e) Reusability [10] and

(f) High sensitivity [11] 
Initially, when the micro-electro-mechanical systems (MEMS) [12], fabricated using microfabrication technology, are used for numerous sensing applications, the high fabrication cost and the level of complexity involved prohibited this technology to be implemented on a broad scale. For example, micro accelerometers used in car airbags, microphones in cellular communication, and cantilevers in atomic force microscope (AFM) [12] are all based on microfabrication technology. In recent years, biological microelectromechanical systems (bioMEMS) have also shown promising results in both research and industry [13]. Secondly, fieldeffect transistors (FETs), though patented in 1926 by Julius Edgar, were first realized as practical devices by physicists in 1947 and were purely based on an inorganic semiconductor. The major disadvantage of the inorganic FET-based sensors is the cost involved in the manufacturing process and the cost of semiconductor materials ( $\mathrm{Si}, \mathrm{Ge}, \mathrm{GaN}, \mathrm{GaAs}$ ). In spite of faster switching speeds and reduced operating voltages, sensors made of these inorganic FETs can address only certain applications due to a lack of sensitivity and/or selectivity for various environmental conditions. Spectroscopy is the third technology commonly used to detect analytes, different physiological parameters, and other physical properties. Morpho, an ion-mass spectroscopy-based handheld device, is successful and is used by the US army in the event of explosion to analyze explosives used. All of the above techniques need complex units to be built at high manufacturing costs, moreover, the data produced from different sensors are in different forms making it a challenge to build electronic nose platforms consisting of various pattern recognition approaches, for extracting any meaningful information out of these sensing platforms. Orthogonality in sensing, though discussed widely as a way to address the selectivity issues, remains a challenge for experimentalists. 
Organic materials have been studied for over five decades, and there are numerous applications for these materials in the field of microelectronics. In the microfabrication industry alone, these polymers are used as gate insulators, photoresists, sacrificial layers, and encapsulation. However, currently, they are also being used as an active organic semiconducting thin-film for OFETs. In addition to their application as an electronic device, OFETs are also being used for multiple sensing applications, such as chemical sensing, biological sensing, humidity sensing, and ionizing radiation sensing. There has been a tremendous push to improve the performance of the OFET sensors to attain higher sensitivity and selectivity by using state-of-the-art techniques. However, organic electronic devices still need to be optimized to demonstrate reliable performance. Such a research on optimization could contribute to the evolution of low-cost and highly reliable sensors to assess the environment and human health, leading to a plethora of applications.

This review article discusses the feasibility and different aspects of the OFET sensors for environmental sensing and bio-sensing applications. Though, there are review articles available on OFET based sensing due to the ever-increasing output of scientific publications [14-17], a specific topic of multi-parametric sensing and the probability of integrating OFET based sensors into a system has been chosen. This article also gives an overview of the advantages associated with the OFET sensors with the hope of pushing the boundaries of the research.

\section{Sensing mechanisms for sensors}

Sensing mechanisms for different gases, chemicals, pressure, and irradiations are complex and diverse due to various physical and chemical effects. In some cases, the sensing materials may change physical properties, such as stress, temperature, and doping. Also, the limit of detection 
(LOD) of various analytes varies from sensor to sensor, and the necessity to adhere to LOD, in turn, depends on analyte concentrations. In view of this, a few important (and widely used) mechanisms pertaining to sensors are discussed in this section. Fig. 1 shows two schemes, where we propose the mechanisms for multi-parameter sensing (a) and in Fig. 1b we show sensing capability of OFET for similar environmental/biological parameters.

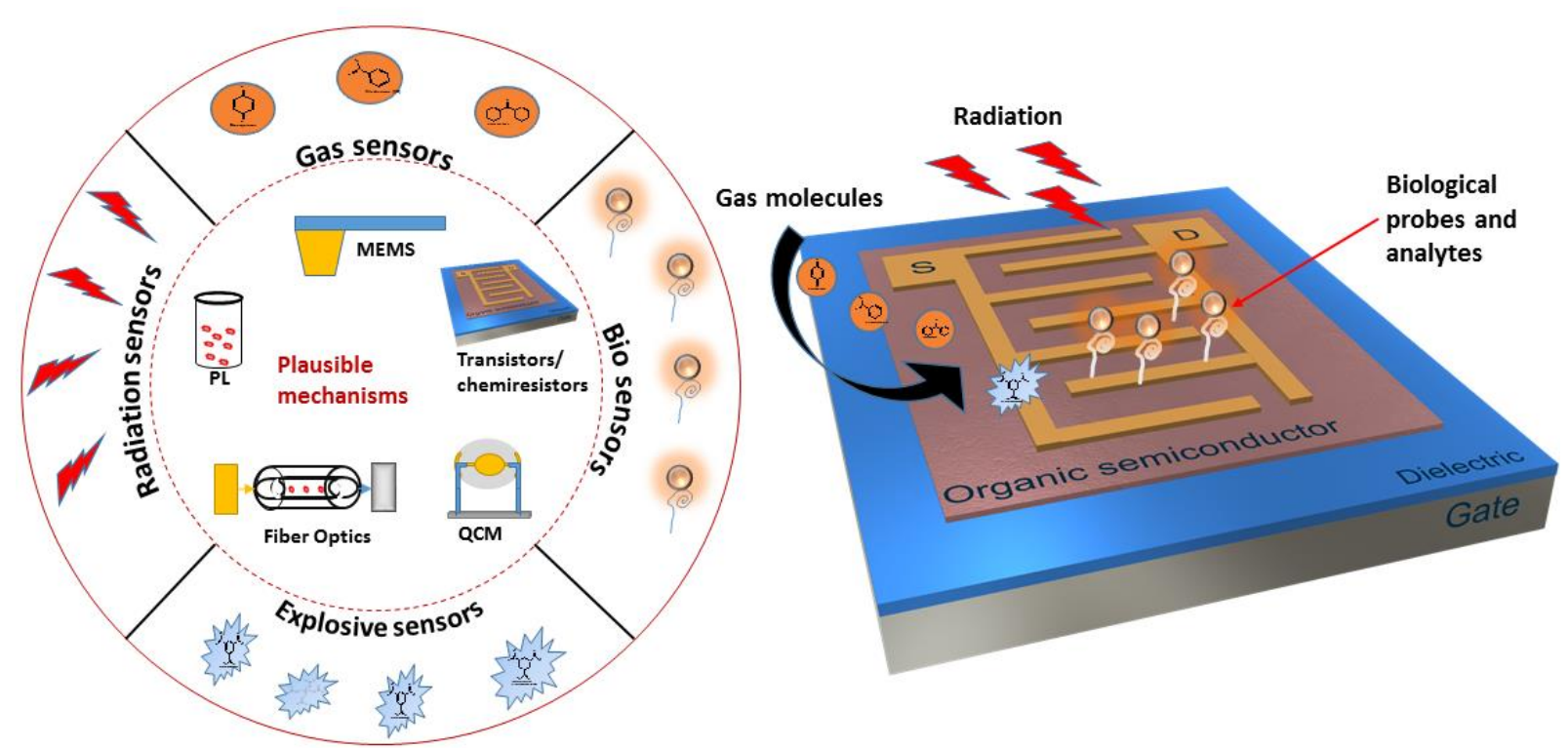

Fig. 1. (a) Applications and mechanisms scheme and (b) proposed schematic for OFET based multi-environmental parameter sensor.

Oxidation and reduction mechanisms have been in use for a long period to exploit the goal of sensing. Recently, Tian et al. used $\mathrm{ZnO}$ nanorods and Pt nanoparticles for the detection of ethanol and $\mathrm{NO}_{2}$ gas [18]. The detection process is explained with the help of a change in the resistance of the pristine $\mathrm{Pt} / \mathrm{ZnO} /$ nanosheet stack using reduction (Ethanol) and oxidation (for $\mathrm{NO}_{2}$ ) mechanisms. Immediately upon exposure to air, $\mathrm{O}^{-}$species accumulate all around the $\mathrm{Pt}$ nanoparticles. These species, when they interact with ethanol, increase the accumulation of electrons on the surface thereby decreasing the resistance of the pristine $\mathrm{Pt} / \mathrm{ZnO} /$ nanosheet. In the case of $\mathrm{NO}_{2}$ sensing, a reverse phenomenon increases the resistance while forming a depletion 
layer of $\mathrm{O}^{2-}$ ions on the $\mathrm{ZnO}$ surface. Thus, a chemiresistive sensor was demonstrated successfully with help of a stack of materials ( $\mathrm{Pt} / \mathrm{ZnO} /$ nanosheet) that have excellent charge carrier transport properties. Zhou et al. reported the inter-sheet sensing mechanism of reduced graphene oxide (RGO) while exposed to $\mathrm{CO}_{2}$, which is neither a reducing nor oxidizing gas [19]. The results obtained by the group were explained by the change in resistance due to the structural deformation rather than RGO's charge exchange behavior. Flow-rate of the carrier gas plays a key role in the electrical characteristics of the device. A higher flow rate creates compressive stress on the RGO film reducing the inter-sheet distance which in turn reduces the electrical resistance. On the other hand, a low flow rate creates tensile stress increasing the electrical resistance. Finally, an optimal flow-rate of $300 \mathrm{ml} / \mathrm{min}$ has been chosen for the $\mathrm{CO}_{2}$ sensing.

Quartz crystal microbalance (QCM), a mass sensitive device has been known to be a reliable sensor due to its high sensitivity and measurement accuracy. Sauerbrey's equation is a well-known mass sensitive principle and is used in the QCM

$$
\Delta f=-2.26 * 10^{-6} f_{0}^{-2} \frac{\Delta m}{A}
$$

Where $\Delta f$ is shift in the frequency, $\Delta m$ is change in the mass of the electrode after the analyte interaction, $\mathrm{f}_{0}$ is the resonant frequency of bare QCM and $\mathrm{A}$ is the quartz crystal active area. Sensitivity to analyte is calculated as $\Delta f / \Delta C$, where $C$ is the minimum concentration of the analyte for which the sensor responds. Zhang et al. has recently reported on sensing humidity with polyaniline (PANI)/GO composite. Highest sensitivity of $20 \mathrm{~Hz} / \% \mathrm{RH}$ was reported for 3 layers of PANI/GO composite as compared to the higher number of layers [20]. Photoluminescence based sensing applications span across broad area ranging from explosives to biological analytes. The process involved in optical sensing makes non-invasive and hazardous condition measurements easy. Here, a single excitation light source is used to probe the device under test and the emission 
peaks are monitored. The emitted peak carries the information related to the target analyte or the effect due to the physical parameter under measurement. Different applications like metal ion sensing, gas sensing [21] and glucose monitoring were successfully demonstrated with this mechanism. Similarly, as discussed in the introduction part, FET devices have a different mechanism of sensing. The active channel layer current is modulated when an interaction happens between semi-conductor and the interacting parameter under consideration. Following equation gives more details on the current modulation with respect to device parameters

$$
\begin{aligned}
& I_{D}(\text { lin })=\frac{\text { Cox. } \mu}{2} \frac{W}{L}\left(2\left(V_{G S}-V_{T}\right) V_{D S}-V_{D S}^{2}\right) \\
& I_{D}(\text { sat })=\frac{\text { Cox. } \mu}{2} \frac{W}{L}\left(V_{G S}-V_{T}\right)^{2}
\end{aligned}
$$

Where $I_{D}$ is the drain current, $C_{o x}$ is the capacitance of the dielectric layer, $\mu$ is the effective mobility, $\mathrm{W}$ and $\mathrm{L}$ are the width and length of device, $\mathrm{V}_{\mathrm{GS}}$ gate bias, $\mathrm{V}_{\mathrm{DS}}$ is drain bias and $\mathrm{V}_{\mathrm{T}}$ is the threshold voltage.

\section{Overview of OFETs}

Organic electronic devices (OEDs) have greatly advanced and are presently making their foray into the commercial world. Organic thin-film-based displays already exist in the market, such as mobile phones and PC monitors. The basic building blocks of these displays, the OSCs, have been synthesized and studied for over five decades. Their main advantages are their roll-toroll processing, mechanical flexibility, low/room temperature processing, and potentially low-cost manufacturing. Organic channel materials (OSCs) have also attracted much research, where the charge carrier transportation is taken care of by the ח-conjugated system of OSC. Much like conventional transistors, OFETs allow a controlled current to flow between the source and drain 
electrodes through the modulation of gate voltage. The generic term used for most types of organic transistors is OTFT/OFET; however, there exist several categories of organic transistors depending on the active channel current modulation mechanism, which are out of the scope of this review. Based on their device structure distinguished by the order in which the OSC, dielectric, and metals are deposited, OFETs are primarily categorized into the following.
a. Bottom gate/bottom contact (BGBC)
b. Bottom gate/top contact (BGTC)
c. Top gate/bottom contact (TGBC)
d. Top gate/top contact (TGTC)

Many reports cite the role of oxygen present in atmosphere as an impediment to stability for the OFETs [22, 23]. In this context, TGBC devices have been reported to be more stable than BG due to their OSCs being protected by dielectric and gate layers. However, for sensing devices, the stability is still a challenge due to an interference from the environment. Further, Zang et al. have reviewed device engineering aspects of OFET to improve sensor performance [24]. Interestingly, they were able to identify three key parameters (active layer thickness, receptor implantation (bilayer) and optimization of geometry) to tune the transduction signal and amplify it. In general, active channel layer of an OFET is around several tens of nanometers and acts as an impediment for incoming analyte molecules. Hence, reduction in the channel thickness will always provide scope for improvement in sensitivity and response time [25]. Another important aspect in OFET based sensing is specificity and one needs to add multiple functional groups to the pristine organic semiconductor to achieve the same. This leads to the specific interaction of desired functional groups with the corresponding analyte molecules, but this kind of approach is still under research 
as it is prone to adverse effects like field-effect modulation deterioration. Eventually, a bi-layer approach has been adopted to the device geometry, where another layer of receptor molecule binds covalently or non-covalently to the pristine organic semiconducting layer [26].

Pressure sensing applications were also demonstrated with the help of OFETs, where the geometry has been engineered by introducing additional layer in dielectric, as per the sensing needs. Yin and co-workers [27] exploited such solution-processed bilayer dielectric to fabricate pressure sensors, where poly (methyl methacrylate) PMMA and polyelectrolyte of polyacrylic acid (PAA) are combined together. PMMA/PAA exhibited improved electrical characteristics as the new combination contributed to high capacitance and reduced leakage currents. A TGBC geometry OFET has been fabricated with a conjugated polymer (PIDT-BT) as OSC and PMMA/PAA duo as dielectric layer on top of a flexible substrate (PET sheet). Further, it is shown that a reduced thickness in PMMA layer down to $30 \mathrm{~nm}$ improves both capacitance and mobility. Also, a record sensitivity of $56.15 \mathrm{KPa}^{-1}$ has been achieved in $19.2 \mathrm{~ms}$ at an operating voltage of $-5 \mathrm{~V}$.

\section{Sensing using OFETs}

Organic semiconducting materials have also been used as the receptor layer for devices in sensor applications. The advantage of using polymers is that the selectivity can be varied with the substitution of various functional groups on the main polymer. Subsequently, these organic materials with unique electronic and mechanical properties have been found suitable for low-cost electronic devices. Depending on the chemical structures in these molecules, their stability varies and make them susceptible to changes in environment. For example, the oxygen content in air and humidity alters the transport properties of the OSCs. In order to address these problems, researchers use gloveboxes with inert environments where the oxygen and humidity levels are 
controlled. Subsequently, the devices are encapsulated inside the box before they are taken out. The table below presents significant information on OFETs used for multiple analytes (gases, explosives, and VOCs) sensing, and they do not have any encapsulation.

Table 1: Summarizing OFET sensors for various analytes

\begin{tabular}{|l|l|l|l|l|l|}
\hline $\begin{array}{l}\text { OFET } \\
\text { Configuration }\end{array}$ & $\begin{array}{l}\text { Organic } \\
\text { Semiconductor }\end{array}$ & Analytes & $\begin{array}{l}\text { Detection } \\
\text { Limit }\end{array}$ & $\begin{array}{l}\text { Selectivity } \\
\text { study }\end{array}$ & Reference \\
\hline BGTC & P3HT/ZnO/GO & $\mathrm{NO}_{2}$ & $1 \mathrm{ppm}$ & No & {$[28]$} \\
\hline BCTG/BGTC & $\begin{array}{l}\text { DPP (LGC- } \\
\text { D148) }\end{array}$ & $\mathrm{NH}_{3}$ & $1000 \mathrm{ppm}$ & No & {$[29]$} \\
\hline BGTC & $\begin{array}{l}\text { Pentacene } \\
\text { ZnO+PMMA } \\
\text { dielectric) }\end{array}$ & $\mathrm{NH}_{3}$ & $10 \mathrm{ppm}$ & No & {$[30]$} \\
\hline BGBC & $\begin{array}{l}\text { PQT12+ TPT- } \\
\text { TTF }\end{array}$ & $\mathrm{TNT}$ & $1 \mathrm{ppt}$ & Yes & {$[31]$} \\
\hline BGTC & DNTT & $\mathrm{NH}_{3}$ & $10 \mathrm{ppb}$ & Yes & {$[32]$} \\
\hline BGTC & $\begin{array}{l}\text { Spirobifluorene- } \\
\text { based polymer }\end{array}$ & $\mathrm{H}_{2} \mathrm{~S}$ & $1 \mathrm{ppb}$ & Yes & {$[33]$} \\
\hline BGTC & PDPPHD-T3 & $\mathrm{xylenes}$ & $40 \mathrm{ppm}$ & Yes & {$[34]$} \\
\hline BGTC & $\begin{array}{l}\text { polycyclic } \\
\text { aromatic } \\
\text { hydrocarbon }\end{array}$ & VOCs & -- & Yes & {$[35]$} \\
\hline BCTG & $\begin{array}{l}\text { Tips-Pentacene } \\
+ \text { PTAA }\end{array}$ & Cysteine & $0.01 \mathrm{mM}$ & No & {$[36]$} \\
\hline BGTC & DPP-TT & PEIE & $0.04 \mathrm{wt} \%$ & No & {$[37]$} \\
\hline & Ethanol & $1000 \mathrm{ppm}$ & No & \\
\hline
\end{tabular}




\begin{tabular}{|l|l|l|l|l|l|}
\hline & & Ethylene & $1000 \mathrm{ppm}$ & No & \\
\hline BGTC & $\begin{array}{l}\text { P3HT -azide / } \\
\text { caliz[8]arene }\end{array}$ & $\begin{array}{l}\text { Methanol in } \\
\text { toulene }\end{array}$ & $1 \mathrm{Vol} \%$ & & {$[38]$} \\
\hline & & $\begin{array}{l}\text { Ethanol in } \\
\text { toulene }\end{array}$ & $1 \mathrm{Vol} \%$ & & \\
\hline & & $\begin{array}{l}\text { n-Hexane in } \\
\text { Toulene }\end{array}$ & $1 \mathrm{Vol} \%$ & & \\
\hline BGTC & DPP2T-TT & Nethene in & $2 \mathrm{Vol} \%$ & & \\
\hline & C8-BTBT / PEI & CH2O & $<1 \mathrm{ppb}$ & Yes & {$[39]$} \\
\hline $\begin{array}{l}\text { BGTC/BCTG/ } \\
\text { PG }\end{array}$ & pBTTT-C14 & BuOH & $<100 \mathrm{ppm}$ & No & {$[40]$} \\
\hline
\end{tabular}

\subsection{OFET sensors for detection of dangerous gases and explosives}

The detection of poisonous gases has been given overwhelming importance in recent years. Like volatile organic compounds, ammonia $\left(\mathrm{NH}_{3}\right)$ is yet another dangerous analyte that is abundant in the atmosphere. Any decaying organic matter can produce $\mathrm{NH}_{3}$, and in normal environmental conditions, it is colorless, caustic (corrosive), and a pungent-smelling gas. Jeong et al. used a DPPbased conjugated polymer to realize a highly sensitive flexible $\mathrm{NH}_{3}$ gas sensing OFET [29]. Here, it is reported that the thinner devices $(\sim 10 \mathrm{~nm}$ DPP $)$ annealed at $150{ }^{\circ} \mathrm{C}$, show a higher sensitivity of $>90 \%$ upon exposure to $1000 \mathrm{ppm} \mathrm{NH}_{3}$ gas (as shown in Fig. 2a) as compared to thicker devices ( $25 \mathrm{~nm}$ as shown in Fig. 2b). Further, the devices showed a negative shift in the transfer curves for prolonged exposure to $\mathrm{NH}_{3}$ due to the formation of trap states in the tail state by chemical interactions. Interestingly, when tuned properly, dielectric layers also play a crucial role in the detection of analytes in OFETs. Recently [30], $\mathrm{ZnO}$ nanoparticles with polymethyl methacrylate 
(PMMA) mixed in 1:1 (v/v) was used for the deposition of a hybrid dielectric layer by spin coating.

Authors [30] chose pentacene as the channel layer and ITO coated glass as substrate for two devices (A) ZnO/PMMA hybrid dielectric and (B) only PMMA. Corresponding transient response is shown in Fig. 2d for both the devices with the same geometry as shown in Fig. 2c.
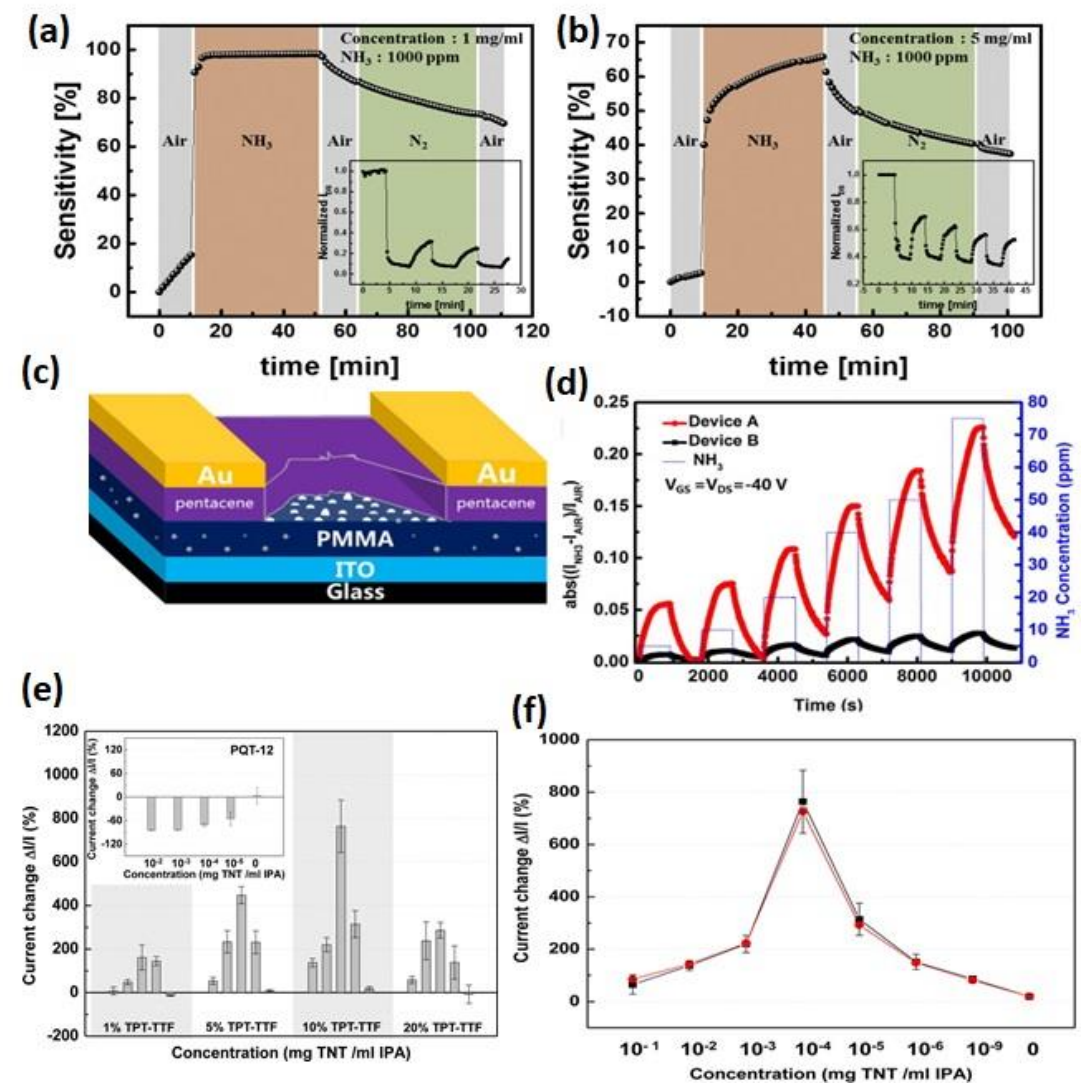

Fig. 2. (a) and 1(b) Sensitivity of $10 \mathrm{~nm}$ and $25 \mathrm{~nm} \mathrm{NH}_{3}$ gas sensors, adapted from Jeong et al.

[29]; (c) and (d) OFET geometry and transient analysis of the same with ZnO/PMMA composite-based dielectric exposed to $\mathrm{NH}_{3}$ gas with various times , adapted from Han et al. [30]

(e) Bar-graph of TNT exposed devices to multiple concentration of TPT-TTF; and (f) Current change $\Delta \mathrm{I} / \mathrm{I}(\%)$ at $\mathrm{VD}=\mathrm{VG}=-40 \mathrm{~V}$ of blended PQT12:10\% TPT-TTF with a maximum at $\sim 10^{-4}(\mathrm{mg}$ TNT/ml IPA), adapted from Katz et al. [31]

Device A is highly sensitive compared to device B due to the small grain size and adsorption of oxygen on the surface of the $\mathrm{ZnO}$ nanostructure. In the first case, the small grain boundaries indicate more $\mathrm{NH}_{3}$ adsorbing sites, and in the later, the adsorbed oxygen on the $\mathrm{ZnO}$ reacts with the $\mathrm{NH}_{3}$ and releases electrons, reducing the barrier height leading to a decrease in $\mathrm{ZnO}$ resistance [30]. Similarly, the detection of trace chemical explosives using OFETs has been extensively 
investigated by the Katz group at John Hopkins University, who are developing multiple platforms and processes to detect explosives that are both air-borne and water-borne. Later, the same group demonstrated a dilute TNT analyte solution detector with the PQT12:TPT-TTF blend OFETs [31]. Katz et al. have chosen BGBC geometry for the sensors, while both pristine PQT12 and its blends were used as a channel-cum-receptor layer. Four different blends made of PQT 12 and TPT-TTF $(1,5,10$ and $20 \mathrm{wt} \%)$ were tested with different concentrations of TNT in IPA. A maximum response in terms of change in current $\Delta \mathrm{I} / \mathrm{I}(\%)$ was obtained with PQT12:10\% TPT-TTF blend when exposed to $10^{-4} \mathrm{mg}$ TNT/ $\mathrm{ml}$ IPA, which can be seen in Figs. 2e and 2f. The control studies done with pristine PQT12 did not show any response with neither a varying concentration of TNT nor with other analytes, such as 2,4-DNT, 2,6-DNT, and Amino-2,6-DNT, whereas the PQT12:10\% TPT-TTF blend was highly selective to TNT among all of these analytes and also showed varying sensitivity towards various concentrations of TNT in IPA. The sensing mechanism was ascribed to the TNT molecules that quench the functional groups of TTF, thereby allowing the de-trapping of holes and causing the current to increase in the channel.

\subsection{OFET sensors for Volatile Organic Compounds (VOCs)}

Organic compounds are chemicals that contain carbon, and VOCs are compounds that easily become vapors and gases. In OFETs, source-drain currents flow in the first few monolayers (in the $\mathrm{nm}$ range) at the interface of OSC and dielectric layers. In order to sense analytes efficiently using OFETs, the channel current in these monolayers needs to be altered by the diffused analyte molecules. So far, with the help of porous structures and by employing ultrathin films, the conducting channel currents have been altered, thereby leading to a gas sensing response of OFET. Khim et al. used the wire-wound bar coating method to attain highly crystalline and ultrathin films $(<2 \mathrm{~nm})$ that can be used for chemical sensing, as shown in Fig. 3a [37]. Further, a thickness 
dependent sensitivity investigation of the active channel layer (of 2 polymers) in OFET was carried out while proving that different morphologies were obtained for different thicknesses. This kind of coating method can be used generically for various platforms (substrates), both flexible and non-flexible. Further, there is no discussion on data obtained and its significance in developing an e-nose system. Addressing this issue, Alona et al. [35] used polycyclic aromatic hydrocarbons (PAH), a p-type semiconductor for the detection of various VOCs, and a classification of these analytes was carried out with a multivariate analysis, as depicted in Figure 3b. The sensitivity of each PAH variant during exposure to different analytes (VOCs) was depicted with the help of a normalized drain current $\left(\Delta \mathrm{I} / \mathrm{I}_{0}\right)$, hole mobility $\left(\Delta \mu_{\mathrm{h}} / \mu_{\mathrm{h}}\right)$, and threshold voltage $\left(\Delta \mathrm{V}_{\mathrm{t}} / \mathrm{V}_{\mathrm{t} 0}\right)$ values. In the case of discontinuous PAH (PAH-2, PAH-3, and PAH-7), transistors exhibited positive and negative $\mathrm{V}_{t}$, for with HTS and without HTS surfaces. Whereas, in the case of PAH-4, the opposite effect was observed.

Apart from that, a discriminant factor analysis (DFA) was implemented using software (SAS JMP) to distinguish between various VOCs. Formaldehyde (HCHO) is one such VOC that gets offgassed from furniture and poses a significant danger to human health. Zhang et al. [39] showed that introducing nanopores to an OFET sensor can improve its sensitivity to low concentrations of $\mathrm{HCHO}$ while reducing the response time and retaining the recovery characteristic to confounding factors (e.g., temperature and moisture). Though they did not explain the improvement in molecular ordering due to introduction of nanopores, high charge carrier mobilities were obtained with use of a new receptor layer polyethyleneimine (PEI). The presence of a PEI layer on top of $\mathrm{C}_{8}$-BTBT caused electron doping of the latter and brought the current down. Further, when carbonyl groups of $\mathrm{HCHO}$ interact with amine groups of PEI, the $\mathrm{C}_{8}$-BTBT layer is de-doped and 
currents are regained. Thus, both factors (nanopores and PEI layer) improved the sensitivity and response time of the OFET sensor.
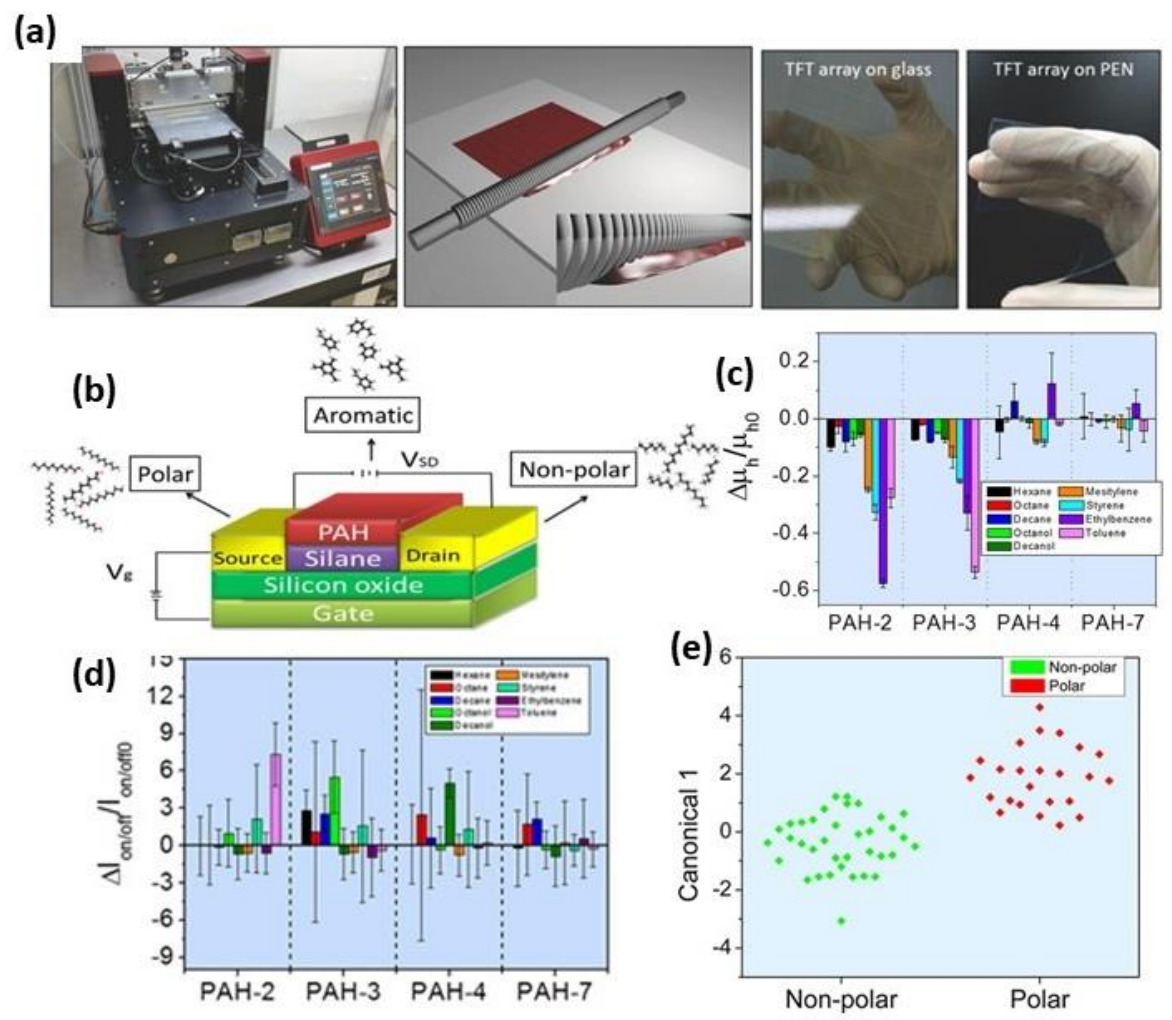

Figure 3. (a) Bar-coating machine and the bar used for fabricating TFTs on glass and PEN sheet, adapted from Khim et al. [37]; (b) schematic of OFET exposed to different analytes; (c) normalized mobility $(\Delta \mu \mathrm{h} / \mu \mathrm{h} 0)$ values while exposing the devices studied to different analytes;

(d) normalized average current ratio $\left(\Delta \mathrm{I}_{\mathrm{on}} / \mathrm{I}_{\mathrm{off}}\right)$ values while exposing the devices studied to different analytes; (e) discriminant factor analysis (DFA) of the polar materials and the non-polar materials at different concentrations, adapted from Alona et al. [35]

\subsection{OFET sensor for ionizing radiation dosimetry}

Owing to their sensitivity towards various environmental conditions, gases, and chemicals, OFETs are gaining acceptance for various sensing platforms and security applications. However, the unstable nature of the organic semiconducting materials is also well reported $[41,42]$. Within the emerging field of OFET sensors, researchers have reported the use of OFETs as 
sensors/detectors for ionizing radiation using organic semiconducting materials, such as $\mathrm{P} 3 \mathrm{HT}$, pentacene, $\mathrm{ZnPc}$, and $\mathrm{CuPc}$. [43,44]. It has been demonstrated that the sensing is due to the impact of high energy ionizing radiation on organic semiconducting materials, which can easily penetrate through the thin passivation layer. Therefore, passivated OFETs can also act as sensors for ionizing radiation while ignoring the environmental instability of organic semiconducting materials [43]. For different types of irradiation, Table 2 summarizes various OSCs used as an active semiconducting layer for an OFET.

Upon exposure to $\gamma$-rays, an increase in the p-type doping and energy stage generation in the band gap of pentacene has been studied, and the pentacene OFETs were proposed as dosimeters for ionizing radiation of $\gamma$-rays by Shilpa et al. [43]. Similarly, the thin-films of CuPc and $\mathrm{ZnPc}$ were reported to have linear dependence of absorption in B and Q-bands upon exposure to $\gamma$ irradiation by Divya et al.; Therefore, OFETs with $\mathrm{CuPc}$ or $\mathrm{ZnPc}$ were proposed to be used as realtime dosimeters for $\gamma$-rays [44].

Basirico et al. [45] investigated X-ray induced photocurrents in TIPS-pentacene thin-films, while Lai et al. [47] employed changes in the electrical characteristics of TIPS-pentacene and proposed the OFETs as a detector with changes in the electrical characteristics upon exposure to X-rays. Fig. 4a shows the experimental setup, and Figs. $4 \mathrm{~b}$ and $4 \mathrm{c}$ show the change in IDs for the OFET upon X-ray exposure. Along similar lines, Paternò et al. [49] exposed a P3HT-based OFET to neutron radiation and demonstrated changes in the electrical properties. While Basiricò et al. [50] studied the degradation of TIPS-pentacene-based OFETs' mobility upon exposure to proton irradiation. A study was conducted by Kim et al [52] on rubrene-based BGTC OFET. They observed the change in the threshold voltage of an OFET with rubrene upon exposure to electron 
beam irradiation, which concluded as n-type doping was induced upon electron beam irradiation to rubrene, as shown in Figs. 4d and 4e.

Table 2: Summarizing reported literature for ionizing radiation sensing and corresponding organic semiconducting materials

\begin{tabular}{|l|l|l|l|l|}
\hline Type of & Energy of irradiation & Organic & OFET & Ref \\
Ionizing & Semiconducting & configur- & \\
Radiation & & Materials & ation & \\
\hline$\gamma$-rays $\left({ }^{60} \mathrm{Co}\right)$ & $1.3 \mathrm{MeV}$ & Pentacene, CuPc & BGBC, & {$[43,44$} \\
\hline X-rays & Several hundreds of keV & BGTC & ] \\
\hline Radiation & ranges from $0.025 \mathrm{eV}$ to $>10 \mathrm{MeV}$ to & (thiophenes $)$ & BGBC & {$[45-$} \\
& $>20 \mathrm{MeV}$ & & BGBC & {$[49]$} \\
\hline Proton & $3-10 \mathrm{MeV}$ & TIPS-pentacene, & BGBC & {$[50,51$} \\
Irradiation & & Pentacene & & ] \\
\hline Electron & Ranges from keV to MeV & Rubrene & BGTC & {$[52]$} \\
Beam & & & & \\
\hline Irradiation & & & & \\
\hline
\end{tabular}



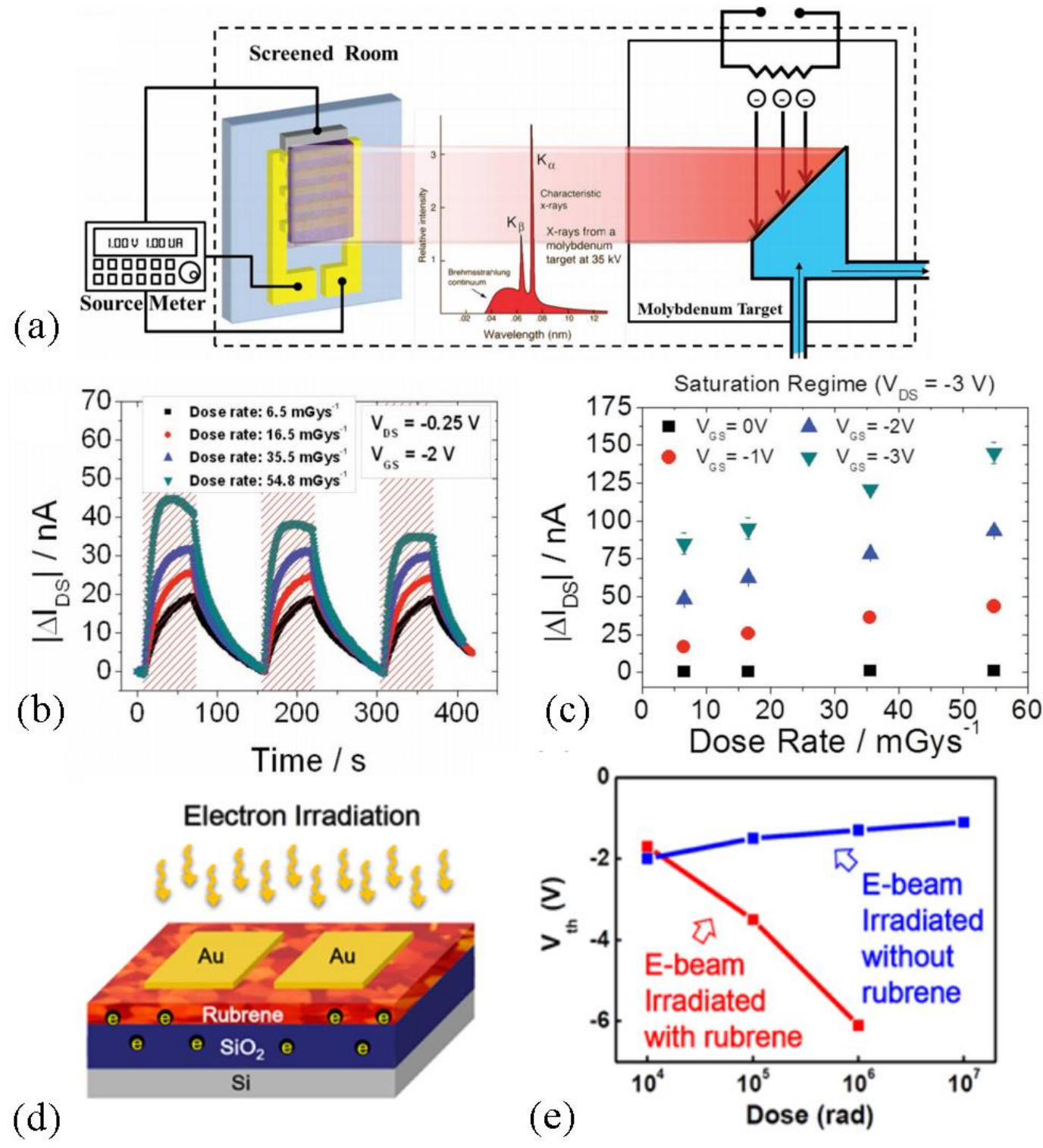

(d)

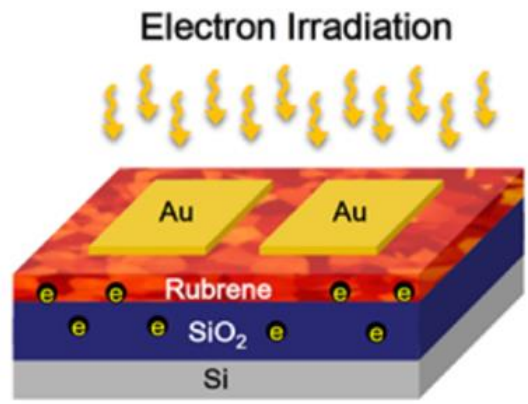

Dose (rad)

Fig. 4. (a) Experimental setup for TIPS-pentacene-based BGBC OFET exposed to X-rays; (b) Observed $\Delta \mathrm{I}_{D S}$ when OFET exposed to X-ray irradiation for different doses; (c) Change in IDs in the saturation regime with $\mathrm{V}_{\mathrm{DS}}=-3 \mathrm{~V}$ demonstrating remarkably high sensitivity of almost 1200 $\mathrm{nC} \mathrm{Gy}^{-1}$, adapted from Lai et al. [47]; (d) Schematic diagram of BGTC Rubrene OFET exposed to electron beam irradiation; and (e) Shift in the $\mathrm{V}_{\mathrm{TH}}$ as observed upon electron beam exposure of rubrene OFET due to induced p-type doping adapted from Kim et al. [52]. 


\subsection{Organic field-effect transistor-based biosensors}

The OFET-based biosensors show promise for detecting low concentrations of biomolecules and studying biochemical interactions [17,53]. A remarkably low concentration $\left(10^{-16} \mathrm{M}\right)$ of dopamine was detected using an electrolyte-gated OFET [54]. The biosensor utilized in the detection was fabricated using transducer material (Pt NPs decorated uniformly on the rGO surface) on a graphene substrate (Fig. 5a). The large-scale graphene worked as a highly conductive template for Pt NPs decoration, which was the main catalyst for the oxidation of dopamine, and the sensitivity of the biosensor was dependent upon the amount of Pt decoration. In another electrolyte gated OFET, during inflammatory cytokine TNF $\alpha$ detection, a minimum detection level of $10^{-10} \mathrm{M}$ was achieved [55]. The OFET device contained a sensing element of anti-TNF $\alpha$ antibody functionalized $\mathrm{Au}$ gated electrode and a channel of a $15 \mathrm{~nm}$ thick pentacene film (Fig. 5b). This device was integrated with a microfluidic system for electrochemical characterization (Fig. 5c). The adsorption of TNF $\alpha$ on the sensing element decreased the hole density, and, as a result, the Fermi level of the pentacene was increased.

The large electrical double-layer capacitance $\left(c a .10 \mathrm{mF} \mathrm{cm}{ }^{-2}\right)$ in electrolyte-gated OFETs is formed at the interface between the OSC layer and electrolyte solution, which is useful for detecting the sub-femtomolar concentration of protein [56]. With this idea, the functional biointerlayer was introduced between the dielectric and the OSC layers to fabricate highly efficient OFET-based biosensors. For the first time, this approach was followed by Magliulo et al. [57]. However, one major drawback of this device structure is a protein layer embedded under OSC layer, which limits the availability of target molecules to reach the protein layer for detection. Attempts have been made to tailor the sensing performance of the OFET-based biosensors to detect/catalyze the specific analytes $[58,59]$. However, it is important to anchor the bio-recognition 
elements/enzymes with the OSC layer for biosensing. To investigate the effect of protein detection parameters, Hammock et al. functionalized ultrathin PVP-HDA dielectric and DDFTTF-based OFETs using Au NP binding sites followed by a thrombin-specific aptamer attachment and a BSA treatment before thrombin exposure to the device, as seen in Fig. 5d [58]. A PDMS flow cell was designed to deliver thrombin directly on top of the OFET biosensor (Figure 5e). During validation of thrombin sensitivity, the current response of the biosensor was decreased while increasing the thrombin concentration, and a nonlinear sensitivity was observed with a lower detection limit of $100 \mathrm{pM}$ (Figs. $5 \mathrm{f}$ and $5 \mathrm{~g}$ ). Shen et al. used a plasma-assisted-interfacial-grafting method to tailor the neighboring-conductive-channel of OFET and also assembled an antenna onto the surface of OFET, which enables direct interaction of target analytes in the solution [59]. Due to direct and specific interaction, the sensor detected adenosine triphosphate (ATP) at a very low concentration of $0.1 \mathrm{nM}$. Also, reproducibility and selectivity were other enhanced properties.

The enzyme-based OFETs offer an advantage of excellent selectivity and sensitivity for specific analytes during electrochemical reactions [60,61]. Minami et al. used bipyridinium derivative as an electron-transfer mediator to functionalize the extended gate, which also supported nitrate reductase enzyme [60]. Sodium dithionite in aqueous solutions served as an electron donor during nitrate reduction that was detected by changing the electrical characteristics of the OFET biosensor. The change in the channel conductance upon the addition of nitrate was noticed because of an enzymatic reaction. A low limit of detection (45 ppb) and high sensitivity was achieved. In another report, Minami et al. fabricated a novel flexible extended-gate OFET [61]. The surface was modified with lactate oxidase and horseradish peroxidase osmium-redox polymer to detect lactate levels selectively (Fig. 5h). The transfer characteristics of the fabricated OFET showed a negative shift of the transfer curve while increasing the lactate concentration (Fig. 5i). A linear 
relationship was seen in the low concentration range and the limit of detection was $220 \mathrm{nM}$ (Fig. $5 j)$. Furthermore, the sensors were highly selective for lactate when measured in the presence of other biomolecules and ions (Fig. 5k). OFET-based biosensors thus opened up a novel opportunity for low-cost and flexible bioelectronic devices. There are however some technical challenges, including the instability of the organic materials in aqueous media. 

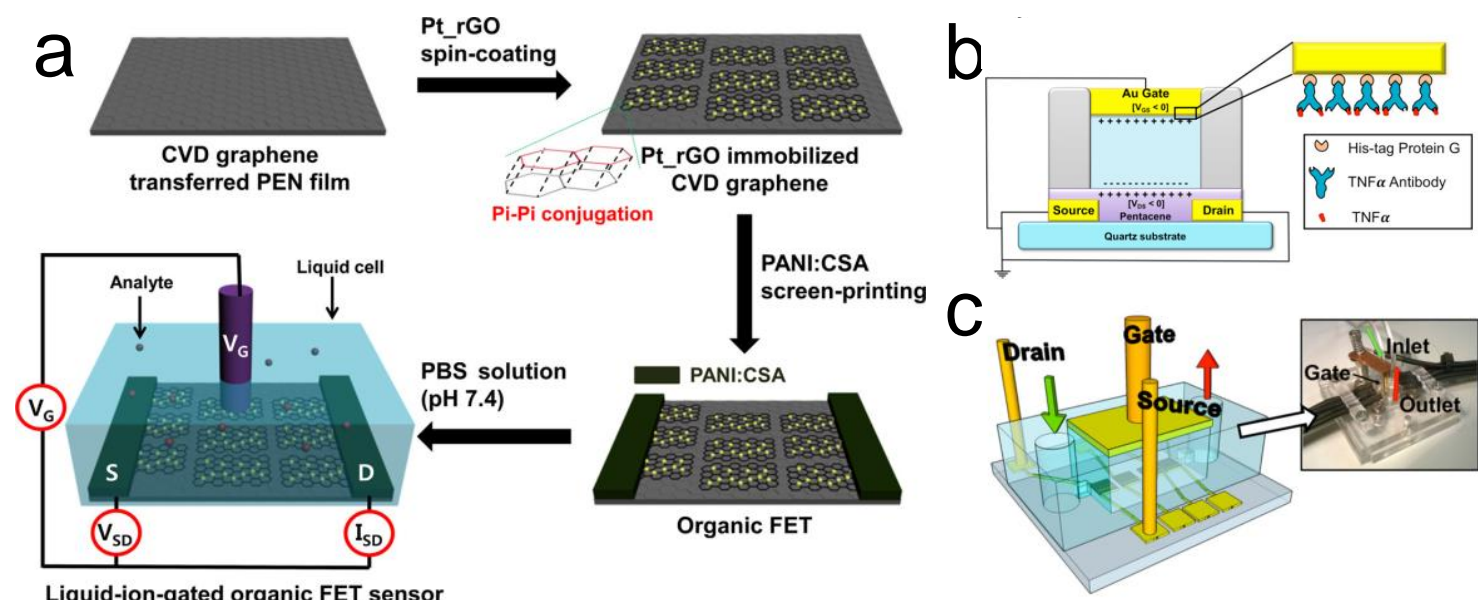

Liquid-ion-gated organic FET sensor

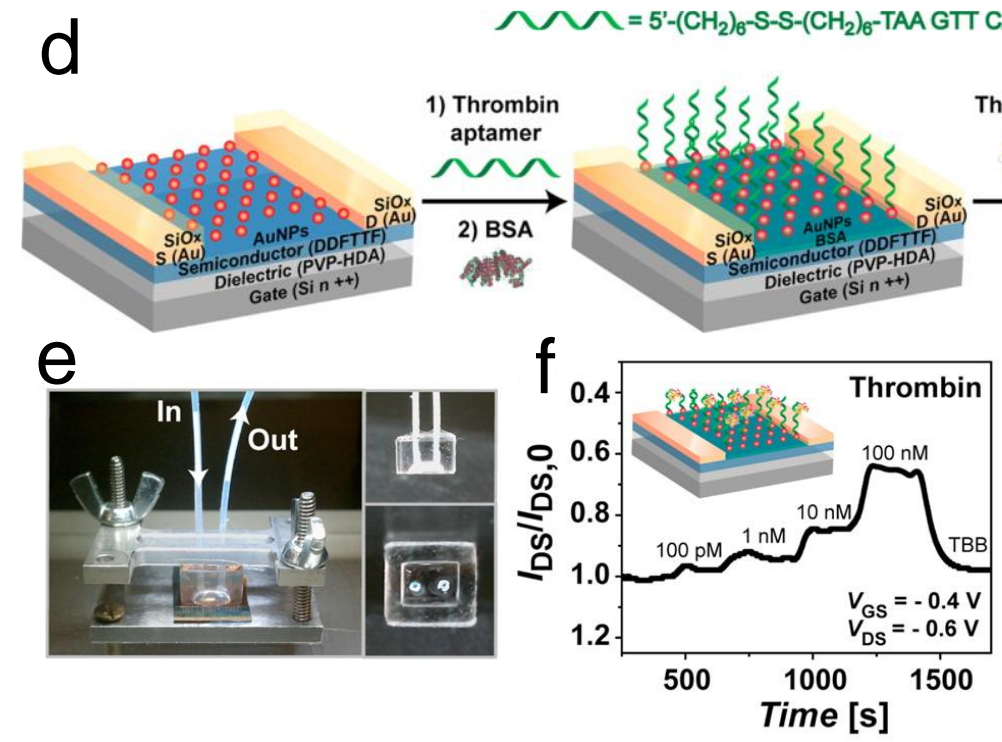

$\sim \sim$ = 5'-( $\left(\mathrm{CH}_{2}\right)_{6}$-S-S- $\left(\mathrm{CH}_{2}\right)_{6}$-TAA GTT CAT CTC CCC GGT TGG TGT GGT TGG T-3'
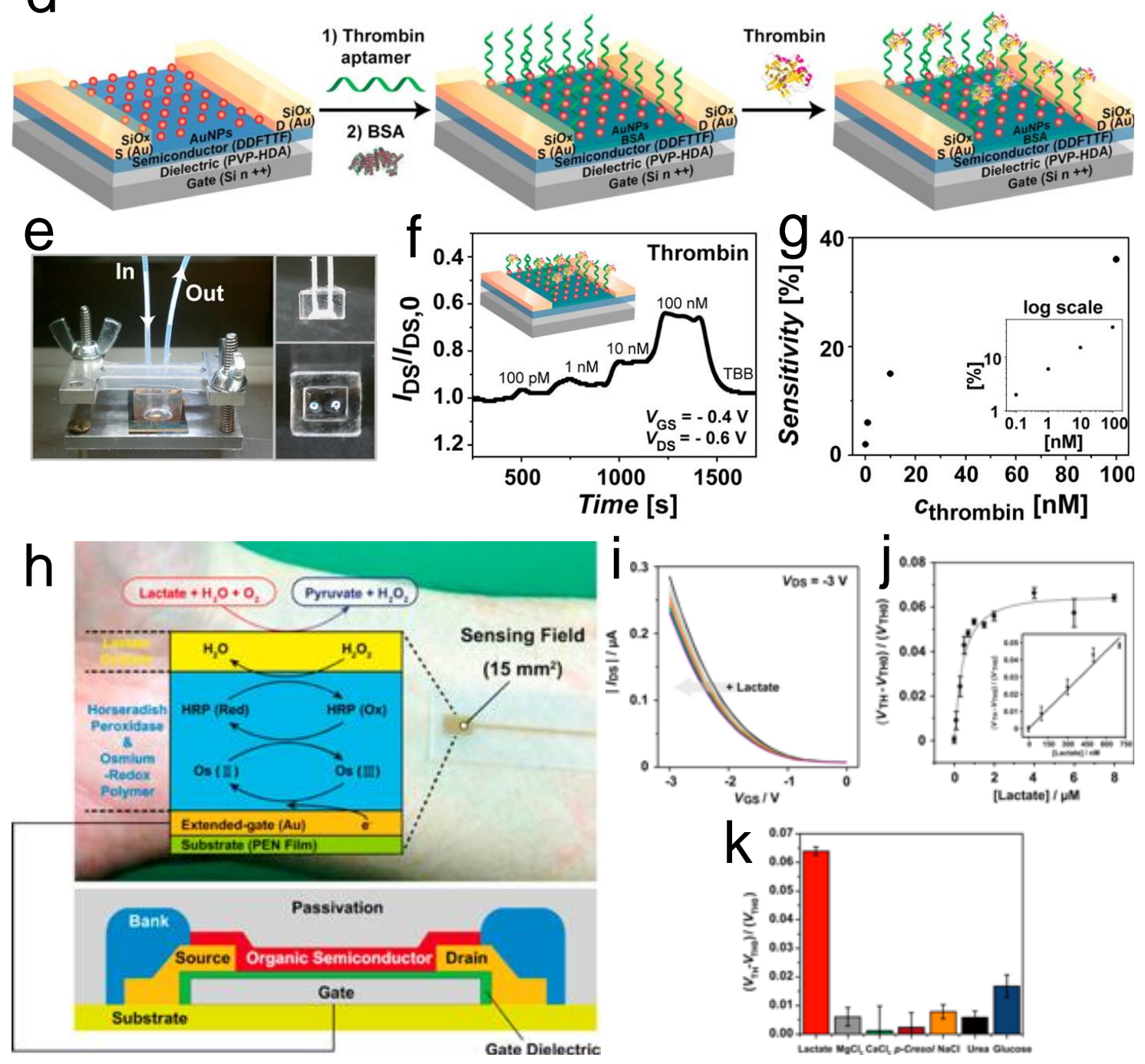

Figure 5. (a) Schematic illustrating fabrication sequence of an OFET-based sensor, adapted from Jungkyun et al. [54]; (b) Schematics of the EGOFET device; (c) Drawing of the microfluidics with optical image showing experimental setup, adapted from Basiricò et al. 
[55]; (d) Fabrication of OFET-based sensor for detection of target protein; (e) PDMS flow cell; (f) response to different concentration of thrombin; (g) Calibration plot, adapted from Hammock et al. [58]; (h) Flexible OFET layout and optical image of OFET-based lactate biosensor attached on wrist; (i) transfer characteristics; (j) calibration curve; and (k) selectivity test, adapted from Minami et al. [61].

\section{Future directions of the research}

An important aspect that requires considerable attention is the quantitative analysis of the threat that arises due to dangerous analytes, such as dangerous gases, chemical vapors, explosives, VOCs, leaks of ionizing radiation, and/or various bio-chemicals. As discussed in this article, being sensitive to many of these analytes, OFET-based sensor platforms have to be "ghostbusters" with respect to even the minute concentration of these analytes. This means that either the active channel layer or the receptor layer in tandem with active channel should be spatially sensitive to the varying amounts of analytes. To achieve such a response to miniscule changes of analytes, one needs to have control over the composition of organic semiconductor matrix, the pore sizes in the material, or the surface area of the nanoparticles in the receptor elements. Further, the thickness of the thinfilms under test (active channel-cum-receptor site) or the thinning of the receptor layer on top of the active layer of the OFET do not always improve the sensitivity [33]. The optimal thickness has to be figured out in order to achieve the highest sensitivity to the corresponding analyte, while being stable to other environmental factors. With its cost-effective, room-temperature manufacturing process, flexibility, and versatility to be used for sensing applications, the OFETbased ionizing radiation sensing of various types needs further exploration for enhanced sensitivity and stability with different OSCs. With OFET being an electronic device, it is also possible to employ various circuit techniques to enhance sensitivity. 
All the above problems need to be solved depending on the application and the necessity. It is also required to freeze all of the fabrication process parameters, materials (their compositions), and characterization details as discussed so far, as it would help in generating data from identical devices. Additionally, relevant information about sensed analytes needs to be extracted carefully and data analytics (DA) can be implemented to draw conclusions. Part of such DA is pattern recognition, which is the most important element in any sensing system with sensor arrays. It helps in identifying patterns of the data obtained from sensors and then classifying them in accordance with the algorithm. Data mining tools such as principal component analysis (PCA) are employed to reduce the higher dimensional data under test, and its output is used to build prediction models. Machine learning (ML) algorithms are used to learn from the data sets and build these prediction models. That is, we first train the algorithm with the training set and then we test the predicting accuracies with the test set of data. Subsequently, the test data can be used to assess the performance of a PR algorithm in accurately classifying sensor information. This way it helps in more accurately classifying or identifying the samples.

A singular platform that has the capability of embedding different OFET-based sensor arrays that can specifically detect and transduce multi-environmental-parameters is a major challenge due to wide band of variations and degradation of OSCs in environment. For rapid commercialization, bringing down the complexity and the cost, OFET sensors can be employed on flexible substrates with laser-scribed graphene (LSG) techniques [62]. The usage of LSG scribers on top of polymer substrates can be of help in realizing the source, drain and gate contacts. Essentially, only a semiconductor-cum-sensor layer is deposited in such a case, and a device can be readily used as a sensor. Future research can focus on dealing with the long-term drifts associated with sensors, which causes problems in pattern recognition and lead to errors or false alarms. Individual OFET 
sensors need to be taken care of separately in order to deal with such issues. Finally, using an array of OFETs along with pattern recognition can lead to a very reliable e-nose platform. 


\section{References}

[1] F. Röck, N. Barsan, U. Weimar, Electronic Nose: Current Status and Future Trends, Chem. Rev. 108 (2008) 705-725

[2] A. D. Wilson, M. Baietto, Applications and Advances in Electronic-Nose Technologies, Sensors 9 (2009) 5099-5148

[3] C. Di Natale, A. Macagnano, R. Paolesse, E. Tarizzo, A. D'Amico, F. Davide, T. Boschi, M. Faccio, G. Ferri, F. Sinesio, F.M. Bucarelli, E. Moneta, G.B. Quaglia, A comparison between an electronic nose and human olfaction in a selected case study, Solid State Sensors and Actuators (TRANSDUCERS '97) 2 (1997) 1335-1338

[4] C. Wang, P. Sahay, Breath Analysis Using Laser Spectroscopic Techniques: Breath Biomarkers, Spectral Fingerprints, and Detection Limits, Sensors 9 (2009) 8230-8262

[5] S. Some, Y. Xu, Y. Kim, Y. Yoon1, H. Qin, A. Kulkarni, T. Kim and H. Lee, Highly Sensitive and Selective Gas Sensor Using Hydrophilic and Hydrophobic Graphenes, Sci. Rep. 3 (2013) 1868

[6] S. Zhu, X. Liu, J. Zhuang, L. Zhao, A Fast Room Temperature NH3 Sensor Based on an Al/pSi/Al Structure with Schottky Electrodes, Sensors 17 (2017) 1929

[7] S. Roy Morrison, Selectivity in semiconductor gas sensors, Sens. Actuators, 12 (1987) 425440

[8] A.C. Romain, J. Nicolas, Long term stability of metal oxide-based gas sensors for e-nose environmental applications: An overview, Sens. Actuators, B. 146 (2010) 502-506

[9] H. Zeng, T. Takahashi, M.Kanai, G. Zhang, Y. He, K. Nagashima, T. Yanagida, Long-Term Stability of Oxide Nanowire Sensors via Heavily Doped Oxide Contact, ACS Sens. 2-12 (2017) 1854-1859

[10] V. A. Georgobiani, K.A. Gonchar, E. A. Zvereva, L. A. Osminkina, Porous Silicon Nanowire Arrays for Reversible Optical Gas Sensing, Phys. Status Solidi A 215 (2018) 1700565

[11] S. Pandey, Highly sensitive and selective chemiresistor gas/vapor sensors based on polyaniline nanocomposite: A comprehensive review, J. Sci. Adv. Mater. Dev. 1 (2016) 431453

[12] T. R. Albrecht, S. Akamine, T. E. Carver, and C. F. Quate, Microfabrication of cantilever styli for the atomic force microscope, J. Vac. Sci. Technol. A 8 (1990) 3386

[13] A. C. R. Graysonn, R. S. Shawgo, A. M. Johnson, N. T. Flynn, Y.N Li, M. J. Cima, and R. Langer, A BioMEMS review: MEMS technology for physiologically integrated devices, in Proceedings of the IEEE 92-1 (2004) 6-21

[14] X. Wu, S. Mao, J. Chen, and J. Huang, Strategies for Improving the Performance of Sensors Based on Organic Field-Effect Transistors, Adv. Mater. 30 (2018) 1705642

[15] L. Torsi, M. Magliulo, K. Manoli and G. Palazzo, Organic field-effect transistor sensors: a tutorial review, Chem. Soc. Rev. 42 (2013) 8612-8628

[16] T. Someya , A. Dodabalapur, J. Huang, K. C. See, H. E. Katz, Chemical and Physical Sensing by Organic Field-Effect Transistors and Related Devices, Adv. Mater. 22 (2010) 3799-3811

[17] P. Lin, F. Yan, Organic Thin-Film Transistors for Chemical and Biological Sensing, Adv. Mater. 24 (2012) 34-51

[18] H. Tian, H. Fan, J. Ma, Z. Liu, L. Ma, S. Lei, J. Fang, C. Long, Pt-decorated zinc oxide nanorod arrays with graphitic carbon nitride nanosheets for highly efficient dual-functional gas sensing, J. Hazard. Mater. 341 (2018) 102-111 
[19] Y. Zhou, Y. Jiang, T. Xie, H. Tai, G. Xie, A novel sensing mechanism for resistive gas sensors based on layered reduced graphene oxide thin films at room temperature, Sens. Actuators, B. 203 (2014)135-142

[20] D. Zhang, D. Wang, P. Li, X. Zhou, X. Zong, G. Dong, Facile fabrication of high-performance QCM humidity sensor based on layer-by-layer self-assembled polyaniline/graphene oxide nanocomposite film, Sens. Actuators, B. 255 (2018) 1869-1877.

[21] V. M. Zhyrovetsky, D. I. Popovych, S. S. Savka and A. S. Serednytski, Nanopowder Metal Oxide for Photoluminescent Gas Sensing, Nanoscale. Res. Lett. 12 (2017) 132

[22] C.D. Dimitrakopoulos and P.R.L. Malenfant, Organic Thin Film Transistors for Large Area Electronics. Adv. Mater. 14 (2002) 99-117

[23] G. Horowitz, Organic Field-Effect Transistors. Adv. Mater. 10 (1998) 365-377

[24] Y. Zang, D. Huang, CA. Di and D. Zhu, Device Engineered Organic Transistors for Flexible Sensing Applications. Adv. Mater. 28 (2016) 4549-4555.

[25] J. Huang, J. Sun and H. E. Katz, Monolayer-Dimensional 5,5'-Bis(4-hexylphenyl)-2,2'bithiophene Transistors and Chemically Responsive Heterostructures. Adv. Mater. 20 (2008) 2567-2572

[26] M.C. Sportelli, R.A. Picca, K. Manoli, M. Re, E. Pesce, L. Tapfer, C. Di Franco, N. Cioffi, L. Torsi, Surface analytical characterization of Streptavidin/poly(3-hexylthiophene) bilayers for bio-electronic applications, Appl. Surf. Sci. 420 (2017) 313-322.

[27] Z. G. Yin, M.-J. Yin, Z. Y. Liu, Y. Zhang, A. P. Zhang, Q. D. Zheng, Solution-Processed Bilayer Dielectrics for Flexible Low-Voltage Organic Field-Effect Transistors in PressureSensing Applications, Adv. Sci. 5 (2018) 1701041.

[28] Y. Yang and H. E. Katz, Hybrid of P3HT and ZnO@GO nanostructuredparticles for increased NO2 sensing response, J. Mater. Chem. C 5 (2017) 2160

[29] S.H. Jeong, J. Y. Lee, B. Lim, J. Lee, Y.Y. Noh, Diketopyrrolopyrrole-based conjugated polymer for printed organic field-effect transistors and gas sensors, Dyes and Pigments 140 (2017) 244-249

[30] S. Han, W. Huang, W. Shi, J. Yu, Performance improvement of organic field-effect transistor ammonia gas sensor using ZnO/PMMA hybrid as dielectric layer, Sens. Actuators, B, 203 (2014) 9-16

[31] H. Kong, B. Jun Jung, J. Sinha, and H. E. Katz, Electrical "Turn-On" Response of Poly(3,3"'didodecylquaterthiophene) and Electron Donor Blend Transistors to 2,4,6-Trinitrotoluene, Chem. Mater. 24 (2012) 2621-2623

[32] J. Lu, D. Liu, J. Zhou, Y. Chu, Y. Chen, X. Wu, and J. Huang, Porous Organic Field-Effect Transistors for Enhanced Chemical Sensing Performances, Adv. Funct. Mater. 27 (2017) 1700018

[33] A. Lv, M. Wang, Y. Wang, Z. Bo, L. Chi, Investigation into the Sensing Process of HighPerformance H2S Sensors Based on Polymer Transistors, Chem. Eur. J. 22 (2016) 3654.

[34] B. Wang, T. Huynh, W. Wu, N. Hayek, T. T. Do, J. C. Cancilla, J. S. Torrecilla, M. M. Nahid, J. M. Colwell, O. M. Gazit, S. R. Puniredd, C. R. McNeill , P. Sonar, and H. Haick, A Highly Sensitive Diketopyrrolopyrrole-Based Ambipolar Transistor for Selective Detection and Discrimination of Xylene Isomers, Adv. Mater. 28 (2016) 4012-4018

[35] A.Bayn, X. Feng, K. Müllen, and H. Haick, Field Effect Transistors Based on Polycyclic Aromatic Hydrocarbons for the Detection and Classification of Volatile Organic Compounds, ACS Appl. Mater. Interfaces. 5 (2013) 3431-3440 
[36] M. Yun, A. Sharma, C. Fuentes-Hernandez, D. K. Hwang, A. Dindar, S. Singh, S. Choi, and B. Kippelen, Stable Organic Field-Effect Transistors for Continuous and Nondestructive Sensing of Chemical and Biologically Relevant Molecules in Aqueous Environment, ACS Appl. Mater. Interfaces. 6 (2014) 1616-1622

[37] D. Khim, G. Ryu, W.Park, H. Kim, M. Lee, and Y. Noh, Precisely Controlled Ultrathin Conjugated Polymer Films for Large Area Transparent Transistors and Highly Sensitive Chemical Sensors, Adv. Mater. 28 (2016) 2752-2759

[38] M. Y. Lee, H. J. Kim, G. Y. Jung, A-. Han, S. K. Kwak, B. J. Kim, and J. H. Oh, Highly Sensitive and Selective Liquid-Phase Sensors Based on a Solvent-Resistant Organic-Transistor Platform, Adv. Mater. 27 (2015) 1540-1546

[39] F. Zhang, G. Qu, E. Mohammadi, J. Mei, and Y. Diao, Solution-Processed Nanoporous Organic Semiconductor Thin Films: Toward Health and Environmental Monitoring of Volatile Markers, Adv. Funct. Mater. 27 (2017) 1701117

[40] L. M. Dumitru, K. Manoli, M. Magliulo, G. Palazzo, L. Torsi, Low-voltage solid electrolytegated OFETs for gas sensing applications, Microelectron. J. 45 (2014) 1679-1683

[41] C. R. Kagan, A. Afzali, T. O. Graham, Operational and environmental stability of pentacene thin-film transistors, Appl. Phys. Lett. 86 (2005) 193505

[42] M. Manceau, A. Rivaton, J. Gardette, S. Guillerez, N. Lemaître, The mechanism of photoand thermooxidation of poly(3-hexylthiophene) (P3HT) reconsidered, Polym. Degrad. Stab, 94 (2009) 898-907

[43] S. S. Prasad and D. R. Nair, Enhanced Model of Thin Film Organic Field Effect Transistor for Radiation Sensing, Int. J. Sci. Res. 6 (2017) 1258-1261

[44] D. K. Nair and K. S. Kumar, Development of gamma radiation dosimeter using copper phthalocyanine \& zinc phthalocyanine based OFET, IEEE International Conference on Circuits and Systems (ICCS) (2017) 17662327

[45] L. Basirico, A. Ciavatti, T. Cramer, P. Cosseddu, A. Bonfiglio, and B. Fraboni, Direct X-ray photoconversion in flexible organic thin film devices operated below 1V, Nat. Comms. 7 (2016) 13063

[46] A. Kumar, R. Devine, C. Mayberry, B. Lei, G. Li, and Y. Yan, Origin of Radiation- Induced Degradation in Polymer Solar Cells, Adv. Funct. Mater. 20 (2010) 2729-2736

[47] S. Lai, P. Cosseddu, L. Basiricò, A. Ciavatti, B. Fraboni, and A. Bonfiglio, A Highly Sensitive, Direct X- Ray Detector Based on a Low- Voltage Organic Field- Effect Transistor, Adv. Electron. Mater. 3 (2017) 1600409

[48] D. J. Starkenburg, P. M. Johns, J. E. Baciak, J. C. Nino, and J. Xue, Thin film organic photodetectors for indirect X-ray detection demonstrating low dose rate sensitivity at low voltage operation, J. Appl. Phys. 122 (2017) 225502

[49] G.M Paterno, V Robbiano, K.J. Fraser, Neutron radiation tolerance of two benchmark thiophene-based conjugated polymers: the importance of crystallinity for organic avionics. Sci. Rep. 7 (2017) 41013.

[50] L. Basiricò, A. F. Basile, P. Cosseddu, S. Gerardin, T. Cramer, M. Bagatin, A. Ciavatti, A. Paccagnella, A. Bonfiglio, and B. Fraboni, Space Environment Effects on Flexible, LowVoltage Organic Thin-Film Transistors, ACS Appl. Mater. Interfaces. 9 (2014) 35150-35158 
[51] T. Kim, J. Jang, K. Cho, Y. Song, W. Park, J. Park, J. Kima, W. Hong, and T. Lee, Interface effect in pentacene field-effect transistors from high energy proton beam irradiation, Org. Electron. 27 (2015) 240-246

[52] J. J. Kim, J. M. Ha, H. M. Lee, H. S. Raza, J.W. Park, and S. O. Cho, Effect of Electron-Beam Irradiation on Organic Semiconductor and Its Application for Transistor-Based Dosimeters, ACS Appl. Mater. Interfaces. 8 (2016) 19192-19196

[53] M. Magliulo, K. Manoli, E. Macchia, G. Palazzo, and L. Torsi, Tailoring Functional Interlayers in Organic Field-Effect Transistor Biosensors, Adv. Mater. 27 (2015) 7528-7551.

[54] J. Oh, J. S. Lee, J. Jun, S. G.Kim, and J. Jang, Ultrasensitive and Selective Organic FET-type Nonenzymatic Dopamine Sensor Based on Platinum Nanoparticles-Decorated Reduced Graphene Oxide, ACS Appl. Mater. Interfaces 9 (2017) 39526-39533.

[55] M. Berto, S. Casalini, M. Di Lauro, S. L. Marasso, M. Cocuzza, D. Perrone, M. Pinti, A. Cossarizza, C. F. Pirri, D. T. Simon, M. Berggren, F. Zerbetto, C. A. Bortolotti, and F. Biscarini, Biorecognition in Organic Field Effect Transistors Biosensors: The Role of the Density of States of the Organic Semiconductor, Anal. Chem. 88 (2016) 12330-12338.

[56] T. Minamiki, Y. Sasaki, S. Tokito, and T. Minami, Label-Free Direct Electrical Detection of a Histidine-Rich Protein with Sub-Femtomolar Sensitivity using an Organic Field-Effect Transistor, Chemistry Open 6 (2017) 472-475.

[57] M. Magliulo, A. Mallardi, R. Gristina, F. Ridi, L. Sabbatini, N. Cioffi, G. Palazzo, and L. Torsi, Part per Trillion Label-Free Electronic Bioanalytical Detection, Anal. Chem. 85 (2013) 3849-3857.

[58] M. L. Hammock, O. Knopfmacher, B. D. Naab, J. B.-H. Tok, and Z. Bao, Investigation of Protein Detection Parameters Using Nanofunctionalized Organic Field-Effect Transistors, ACS Nano 7 (2013) 3970-3980.

[59] H. Shen, Y. Zou, Y. Zang, D. Huang, W. Jin, C. Di and D. Zhu, Molecular antenna tailored organic thin-film transistors for sensing application, Mater. Horiz. 5 (2018) 240-247.

[60] T. Minami, Y. Sasaki, T. Minamiki, S. Wakida, R. Kurita, O. Niwa, S. Tokito, Selective nitrate detection by an enzymatic sensor based on an extended-gate type organic field-effect transistor, Biosens. Bioelectron. 81 (2016) 87-91.

[61] T. Minami, T. Sato, T. Minamiki, K. Fukuda, D. Kumaki, S. Tokito, A novel OFET-based biosensor for the selective and sensitive detection of lactate levels, Biosens. Bioelectron. 74 (2015) 45-48.

[62] T. He, Y. Yi, X. Dan, C. Ya-Long, M. Wen-Tian, Z. Yuegang and R. Tian-Ling, Wafer-Scale Integration of Graphene-based Electronic, Optoelectronic and Electroacoustic Devices, Sci. Rep. 4 (2014) 3598. 